$\Rightarrow$ OCEANOGRAPHY

\section{Wave threats to the Arctic}

Vulnerable Arctic coastlines have traditionally been protected from wave erosion by the presence of year-round sea ice. However, this protection is increasingly lost due to reduced sea ice related to anthropogenic warming. Extended ice-free seasons - and corresponding expanded open water areas - have also favoured the development and propagation of higher long swell waves, posing an additional threat to coastal regions, including those inhabited by Indigenous communities. Any adaptation efforts therefore require

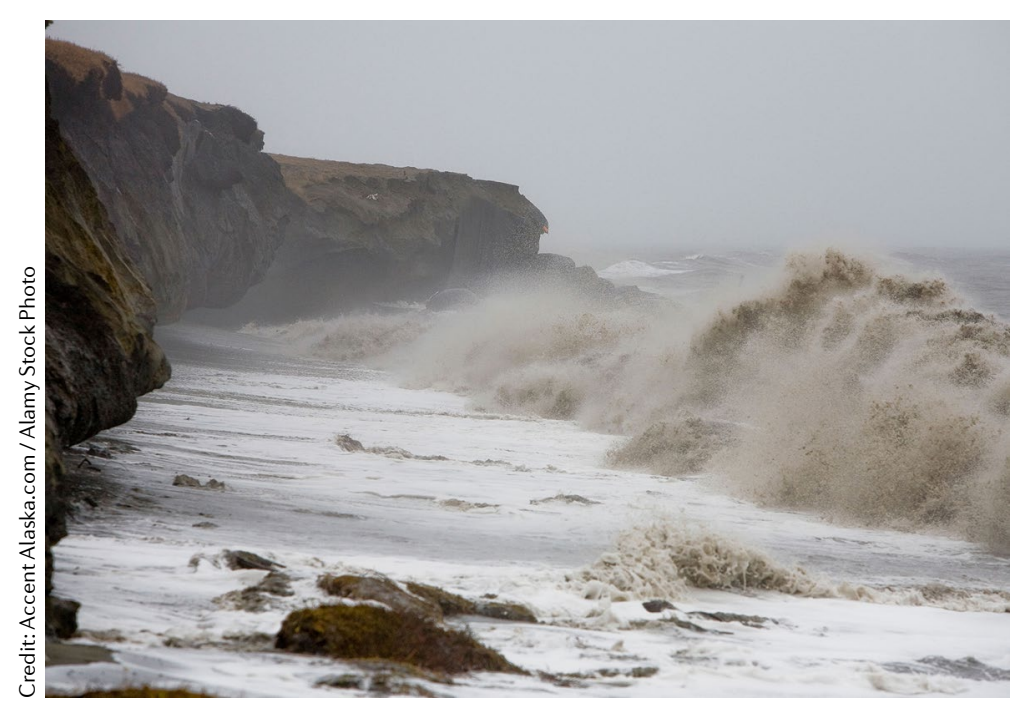

Along the coastline, by contrast, changes are typically $\sim 1-3 \mathrm{~m}$, representing maximum wave heights up to 2-3 times their historical value. Positive increases occur above $70^{\circ} \mathrm{N}$ for the majority of the Arctic in July to November, with peak changes in late autumn arising from interactions between autumn storms and increasingly ice-free oceans. As a result, extreme wave events with large erosion and inundation potential are anticipated to increase in frequency from once every $\sim 20$ years in the historical climate, to once every 1-10 years in the future climate, including in the vicinity of existing Arctic coastal communities.

While results are statistically robust, uncertainty in the specific estimates arises from inter-model variability in surface wind and sea ice concentration projections, the wave modelling technique itself and other complex factors influencing coastal morphology. Nevertheless, the results highlight the vulnerability of Arctic coastal environments and reveal key regions that may benefit from adaptation efforts, including Utqiagvik, Prudhoe Bay, Tuktoyaktuk and other communities along the Beaufort coastline.

Graham Simpkins

ORIGINAL ARTICLE Casas-Prat, M. \& Wang, X. L. Projections of extreme ocean waves in the Arctic and potential implications for coastal inundation and erosion. J. Geophys. Res. Oceans https://doi.org/10.1029/2019JC015745 (2020) 